\title{
Site-Specific Decision-Making Based on RTK GPS Survey and Six Alternative Elevation Data Sources: WATERSHED TOPOGRAPHY AND DELINEATION
}

\author{
C. S. Renschler, D. C. Flanagan, B. A. Engel, L. A. Kramer, K. A. Sudduth
}

\begin{abstract}
Soil erosion modeling and assessment requires substantial and accurate topographic data to obtain meaningful results for decision-making regarding soil and water conservation practices. Today's precision farming equipment includes Global Positioning System (GPS) technology to determine the location of spatially distributed data. Besides the main purpose of tagging site-specific information to a unique location ( $\mathrm{x}$ and $\mathrm{y}$ ), the elevation data $(\mathrm{z})$ recorded has the potential to be used for topographic analysis, including delineation of flowpaths, channels, and watershed boundaries. In addition to GPS-based data collection at various accuracy levels, surveying companies and the U.S. Geological Survey also provide alternative sources of topographic information. Spatial statistical tests were performed to determine if some of these data sources - in particular the ones free of charge or gathered with inexpensive equipment - are sufficiently accurate to represent field or watershed topography and meaningfully apply detailed, process-based soil erosion assessment tools. The most expensive alternatives were most useful for determining elevation and slopes in the flow direction, while there was not much difference between alternatives in obtaining upslope drainage areas and delineation of the channel network and watershed boundary. This is the first of two articles analyzing the impact of the accuracy of six alternative topographic data sources on watershed topography and delineation in comparison to GPS measurements using a survey-grade cm-accuracy GPS.
\end{abstract}

Keywords. Topography, Watershed, Decision making, Global positioning systems, Accuracy, Precision agriculture.

$\mathrm{O}$ ne of the most fundamental requirements for modeling landscape processes is the accurate representation of topography. Detailed and highly accurate digital elevation models (DEMs) or triangular irregular networks (TINs) can be produced using remote sensing techniques, such as traditional aerial photogrammetric surveys, airborne laser scanning (Ackermann, 1999) or interferometric synthetic aperture radar (IFSAR) (Wang et al., 2001). However, using these data sources to represent the topography of a particular site is often too expensive and may require considerable technical and computer expertise for appropriate data handling and processing.

Article was submitted for review in March 2002; approved for publication by the Soil \& Water Division of ASAE in September 2002.

The use of trade names does not imply endorsement by the University at Buffalo (SUNY), Purdue University, or the USDA-Agricultural Research Service.

The authors are Chris S. Renschler, ASAE Member, Assistant Professor, Department of Geography, University at Buffalo - The State University of New York, Buffalo, New York; Dennis C. Flanagan, ASAE Member Engineer, Agricultural Engineer, USDA-ARS National Soi Erosion Research Laboratory, West Lafayette, Indiana; Bernard A. Engel, ASAE Member Engineer, Professor, Department of Agricultural and Biological Engineering, Purdue University, West Lafayette, Indiana; Larry A. Kramer, ASAE Member Engineer, Agricultural Engineer, USDAARS National Soil Tilth Laboratory, Deep Loess Research Station, Council Bluffs, Iowa; and Kenneth A. Sudduth, ASAE Member Engineer, Agricultural Engineer, USDA-ARS Cropping Systems and Water Quality Research Unit, Columbia, Missouri. Corresponding author: Chris S. Renschler, Department of Geography, University at Buffalo - The State University of New York, 116 Wilkeson Quad, Buffalo, NY 14261; phone: 716-645- 2722, ext. 23; fax: 765-494-5948; e-mail: rensch@buffalo.edu.
Field and watershed topography can also be delineated through the use of survey-grade Global Positioning System (GPS) equipment and procedures. Survey-grade GPS equipment differs from the GPS equipment commonly used in precision farming applications in that the GPS satellite signals are processed using a "carrier-phase" positioning technique. This approach is more difficult and expensive to implement than the pseudo-range or "code" positioning technique generally used in precision farming GPS equipment. However, it allows users to obtain much higher levels of accuracy. GPS surveying procedures include static surveys, where the GPS receiver must remain at each point for minutes to hours, and kinematic surveys, where the receiver moves from point to point continuously. Kinematic surveys in which position computations are obtained on-thego are referred to as real-time kinematic (RTK). The RTK GPS technique has become widely used because of its accuracy and efficiency. Descriptions of GPS positioning techniques and applications in agriculture are given by numerous references (Borgelt et al., 1996; Tyler et al., 1997; Clark and Lee, 1998).

Elevation errors are commonly $\mathrm{cm}$-level for kinematic carrier-phase surveys, making this an attractive data source for topographic mapping. Clark and Lee (1998) obtained elevation errors of 4 to $9 \mathrm{~cm}$ when using RTK GPS equipment to determine the topography of field-size areas. Borgelt et al. (1996) reported errors of $12 \mathrm{~cm}$ when comparing kinematic GPS elevations to those obtained using a total station surveying instrument over a small number of locations. Wilson et al. (1998) also used kinematic GPS data to calculate elevation and other topographic attributes, although accuracy statistics were not reported. They found that 
relatively small differences in GPS-derived elevation at individual points could translate into large differences in such parameters as slope gradient and catchment area.

The pseudo-range GPS units commonly used in precision farming also provide on-the-go elevation data, although at a much lower accuracy. Like carrier-phase receivers, they use the differential GPS (DGPS) technique (Tyler et al., 1997) to improve accuracy beyond the level that can be obtained from satellite signals alone. Most pseudo-range DGPS (hereafter referred to as DGPS) receivers used in U.S. agriculture today utilize one of two types of broadcast differential correction signals. The U.S. Coast Guard and U.S. Army Corps of Engineers maintain a network of correction beacons along the coasts and navigable rivers of the U.S. Correction signals from these beacons are available free of charge and cover a substantial part of the agricultural production area in the midwestern U.S. and along both coasts. Another common correction approach is the widearea DGPS correction network. In this approach, corrections are calculated for a virtual base station at the particular location of the receiver based on data from a number of reference stations. Wide-area correction services are available on a fee subscription basis covering the U.S. and many other parts of the world (Tyler et al., 1997). Recently, the free-of-charge Wide-Area Augmentation System (WAAS) has become available in the U.S. WAAS-corrected GPS receivers have been evaluated for applicability in precision farming operations (Shannon et al., 2002).

Many agricultural producers already use DGPS receivers to provide horizontal $(x, y)$ location information for precision farming applications such as yield monitoring and site-specific application of agricultural chemicals. Most DGPS-enabled data collection systems obtain elevation data, but this data has rarely been used in the past due to its relatively low accuracy. Yao and Clark (2000a, 2000b) found that submeter horizontal accuracy DGPS receivers, the type most often sold in recent years for agricultural applications, could be used to develop elevation maps. They obtained vertical errors on the order of 10 to $12 \mathrm{~cm}$ when averaging multiple DGPS data collection passes obtained under controlled error conditions on a small, relatively flat field area. They documented an elevation bias of over $1 \mathrm{~m}$ with the DGPS receiver they evaluated, and cautioned of the need to consider this bias when comparing elevation data from multiple sources. Yao and Clark (2000b) also evaluated DGPS receivers with 2 to $5 \mathrm{~m}$ horizontal accuracies for developing elevation maps. This type of receiver was commonly sold for agricultural applications in the mid-1990s. They found that these less-accurate DGPS receivers were not suitable for topographic mapping.

\section{OBJECTIVES}

This first article in a two-article series analyzes the impact of the accuracy of six alternative topographic data sources on watershed topography and delineation in comparison to measurements using a survey-grade cm-accuracy GPS operated in RTK mode. The following alternatives were compared in pairs based on their spatial applicability/dependency and their costs for data acquisition:

- Alternative A - two methods that are: (1) applicable nationwide, and (2) include costs.

- Alternative B - two methods that are: (1) local/regional dependent, and (2) include costs.
- Alternative C - two methods that are: (1) applicable nationwide, and (2) have no cost.

The main question to be answered in this article is how accurate and cost-effective are each of the alternatives in obtaining elevation data for the analysis of a series of topographic parameters at the field and watershed scale. Instead of gathering GPS data under optimum conditions, as would be done for a standard GPS-based topographic survey (e.g., sufficient number and optimal distribution of GPS satellites in view), the data were collected in a typical contour-parallel, land management pattern while operating at a single speed. This allowed comparison of equipment performance under conditions that mimic the effect of putting the unit on tillage, planting, or harvesting equipment and facilitated an assessment of the equipment's usefulness in topographic analysis and watershed delineation.

\section{Materials}

\section{TEST SiTe Location}

The 30-ha watershed W-2 at the Deep Loess Research Station near Treynor, Iowa (Kramer et al., 1999), was chosen as the test site because this location enabled not only investigating the accuracy of the topographic characteristics based on the various terrain data sets that were already available, but also studying the effects of the different topographic data sets on the accuracy of surface runoff and sediment yield predictions. The USDA-ARS National Soil Tilth Laboratory in Ames, Iowa, administers this research watershed. The measured discharge data at the outlet of this fairly large, entirely agricultural watershed provided the opportunity to compare these measurements with the soil erosion model predictions that are presented in the second article.

\section{DGPS SURVEY}

The most accurate, survey-grade GPS systems that are commercially available are alleged to be as accurate as conventional topographic surveys when operated in a stop-and-go data collection mode. For example, Clark and Lee (1998) found elevation errors of 2 to $3 \mathrm{~cm}$ when mapping a field in this way. Accuracies decrease somewhat when data are collected on a moving vehicle in RTK GPS mode, with errors of 4 to $9 \mathrm{~cm}$ reported by Clark and Lee (1998). The skill level required to successfully complete an RTK GPS survey is high, as is the cost. Therefore, it was desired to investigate other DGPS units and software packages designed such that non-surveyor personnel are able to gather, process, and analyze spatially distributed information with a minimum of additional expertise. In this study, the four different DGPS data sets were collected from four DGPS receiver setups mounted on two all-terrain vehicles (ATVs) during a three-day period just before seedbed preparations on 28 to 30 March 2000 (fig. 1). The DGPS systems mounted on the vehicles included one survey-grade RTK GPS using a local base station for correction, one survey-grade DGPS operating in a lower-accuracy mode with Coast Guard beacon correction, and two systems commonly used for precision farming applications.

Two DGPS units were mounted on each ATV. Each DGPS unit had a separate antenna and data logger (fig. 1). The continuous 1-second DGPS measurements took place while 


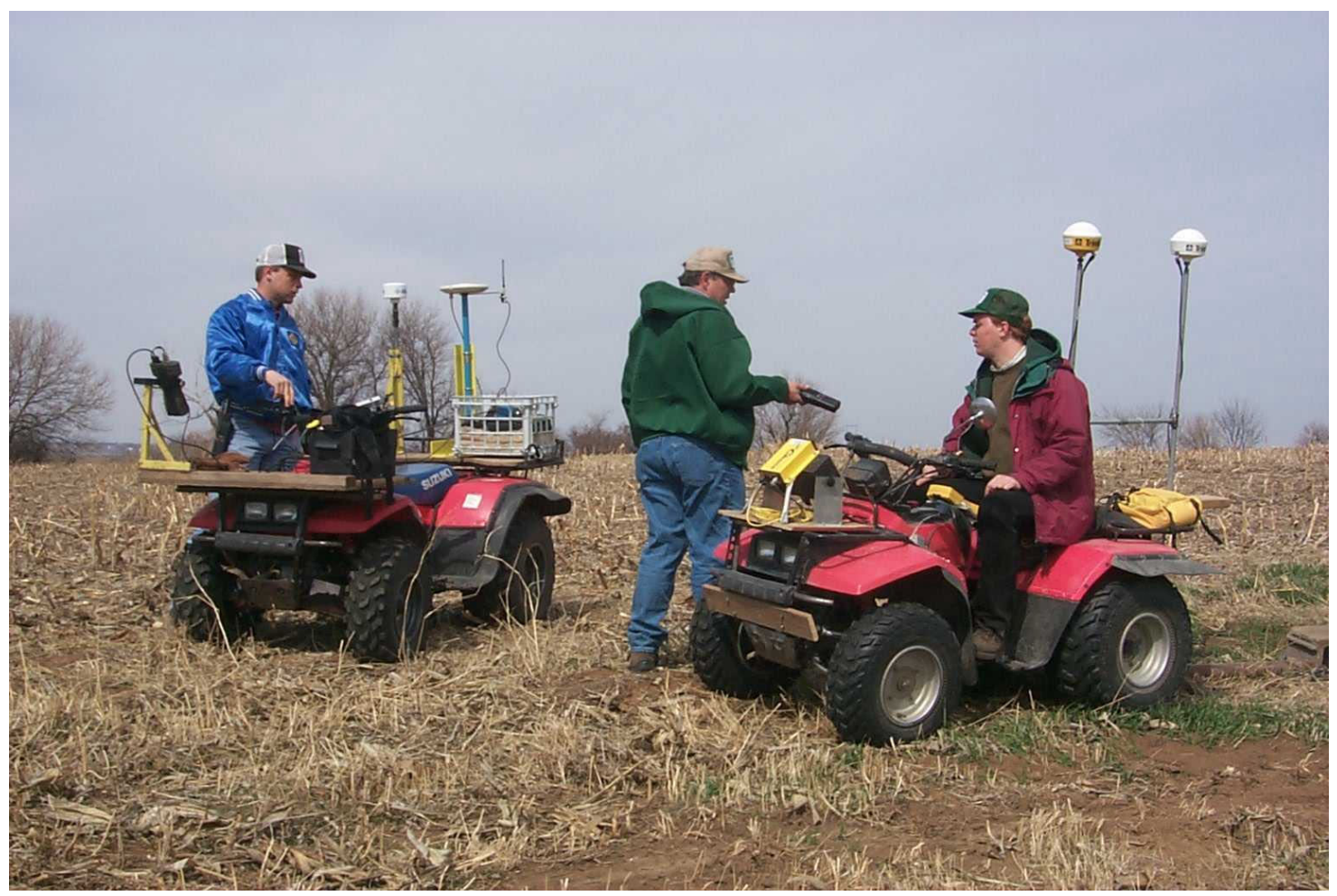

Figure 1. Experimental setup of four Differential Global Positioning System (DGPS) receivers mounted on two all-terrain vehicles (ATVs) for gathering precision farming-type topographic data.
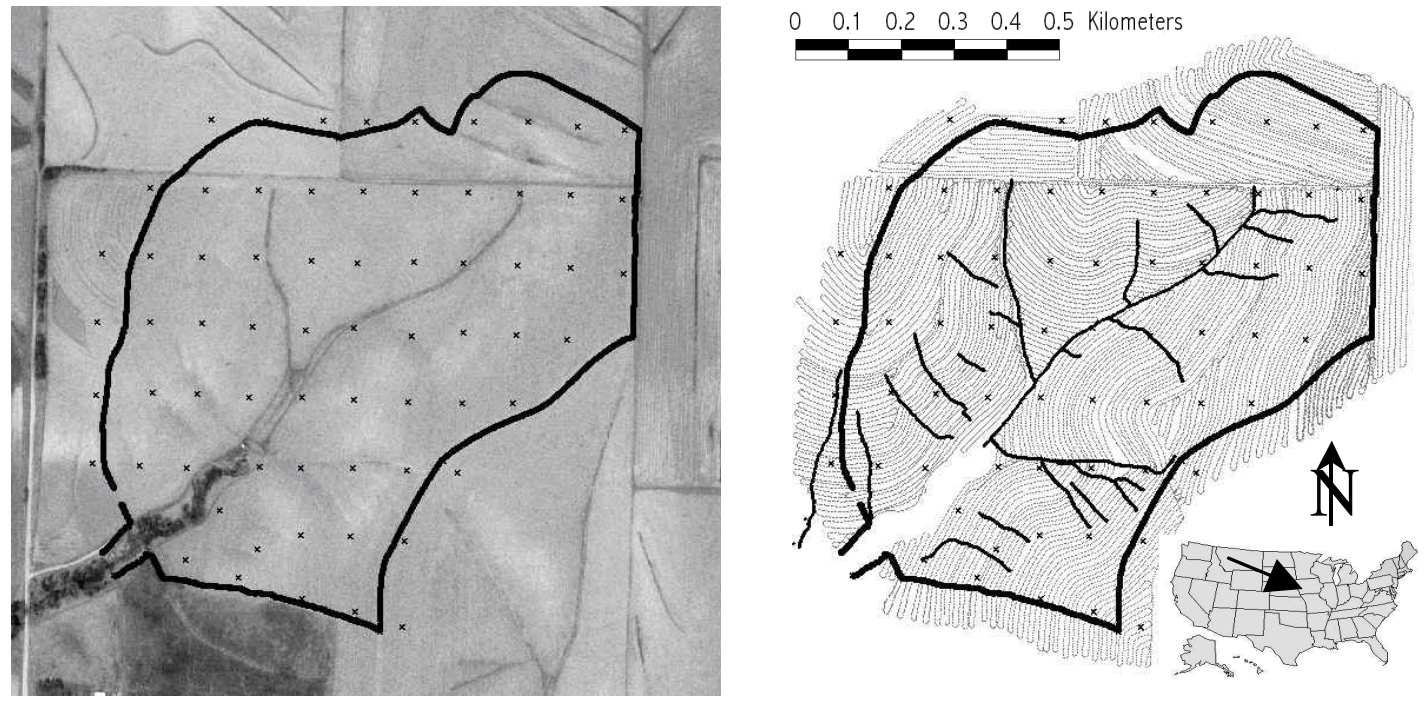

Figure 2. Field survey checkpoints and watershed outline (left image) and mapped ephemeral gullies and GPS data tracks (right image) gathered for watershed W-2 at Treynor, Iowa. Note that no GPS measurements were taken below the gully headcut (indicated by trees in southwest corner of W-2).

operating both ATVs with a management speed $\left(10 \mathrm{~km} \mathrm{~h}^{-1}\right)$ and a 5 to $10 \mathrm{~m}$ distance between vehicles as they traversed all management strips in a contour parallel way $(\sim 4 \mathrm{~m}$ spacing) in the 30-ha watershed W-2 (fig. 2). The management speed and path width were chosen based on the typical management practice in this region. In addition to the DGPS data sets, watershed boundary, lines of accumulated surface flow (such as gullies and defined channels), and a more or less regular raster of 68 checkpoints were mapped with the RTK GPS for accuracy testing of all available elevation data sets to represent these watershed characteristics at these locations (fig. 2).
The most precise data were gathered with the pair of survey-grade RTK GPS units - one as base station and one on the ATV (table 1). These measurements, taken by the comparatively expensive equipment (\$50,000 US) with horizontal accuracy of 1 to $3 \mathrm{~cm}$ and vertical accuracy of 2 to $6 \mathrm{~cm}$ (as described by its manufacturer), were used as a benchmark to compare all other data sources. The RTK GPS base station was established over a known point at the edge of the experimental watershed. The location of this point had been previously determined with the survey-grade DGPS operating in static mode. 
Table 1. Topographic data sources, approximate data or equipment costs, and vertical accuracies. ${ }^{[a]}$

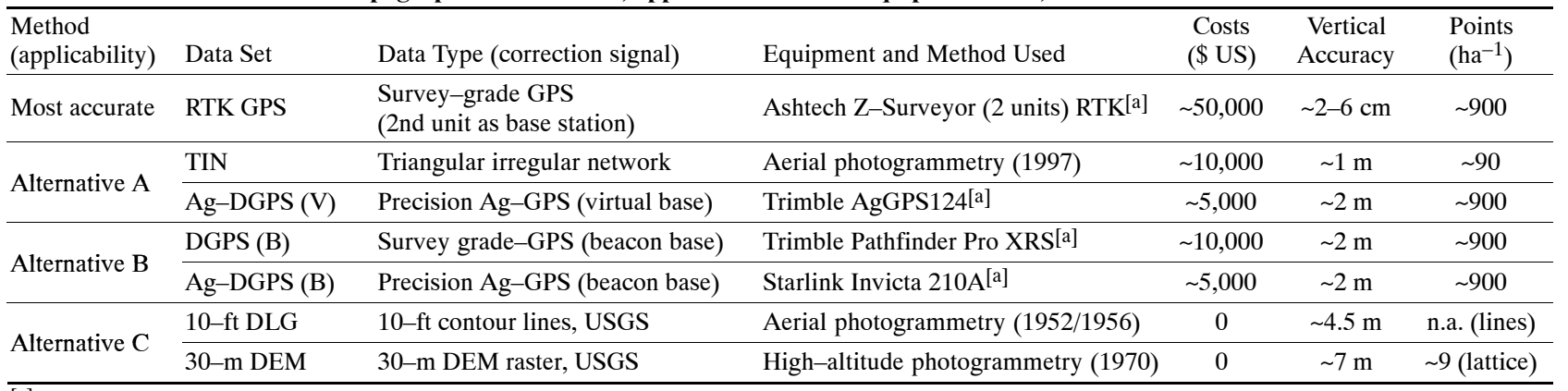

[a] Magnitude of costs for the different GPS receivers in Spring 2000; vertical accuracies provided by equipment or data provider.

\section{Alternative A}

As an alternative to the expensive, survey-grade RTK GPS system, alternative A provided the next most accurate terrain information. A low-altitude photogrammetric survey was conducted by a contractor for the test site in 1997 and consisted of points in a triangular irregular network (TIN). The surface of the TIN was based on a regular grid of point measurements (TIN nodes) every $15 \mathrm{~m}$ combined with additional point measurements spaced down to $1 \mathrm{~m}$ at distinct changes of topography such as fences, terraces, channels, or gullies. The point density for the irregular point survey was an average of 90 points per ha, which is an order of magnitude lower than all of the DGPS data sets. Alternative A also included a precision agriculture DGPS (Ag-DGPS) RTK unit with a nationwide available correction signal from a virtual base station provider (Omnistar).

\section{Alternative B}

Alternative B was either a single survey-grade GPS or a less expensive precision agriculture DGPS unit. Both units obtained a correction signal from the closest U.S. Coast Guard/Corps of Engineers beacon station (about $25 \mathrm{~km}$ to Omaha, Nebraska). Much of the crop-producing area of the U.S. is within range of one or more stations in this correction network; however, the accuracy of the correction degrades with increasing distance from the correction station. Thus, alternative B would only be of localized application, usable within the effective range of Coast Guard beacon station corrections. It should be noted that this survey-grade GPS receiver could have provided a higher accuracy if it had been operated with another, paired unit as the base station for the correction signal. Although capable of $\mathrm{cm}-\mathrm{level}$ accuracies in some modes, it was limited to sub-meter horizontal (approximately sub-two-meter vertical) accuracy when using the beacon correction signal on a moving platform.

\section{Alternative C}

Alternative $\mathrm{C}$ - the no-cost option - used either contour lines from topographic maps or a $30-\mathrm{m}$ raster DEM, both provided by the U.S. Geological Survey (USGS). The U.S. National Map Accuracy Standards allow 10-ft contour lines on a topographic map at the $1: 24,000$ scale that have no more than $10 \%$ of randomly tested elevation points with errors of more than 1.5 times the distance between contours (U.S. Bureau of the Budget, 1947). The 30-m Level 1 DEM ( 9 points per ha) is the less accurate of the two commonly available DEM sources. USGS DEMs have variable resolution and accuracy depending on their origin: Level 1 DEMs are generally derived from high-altitude photogrammetry with a vertical resolution of $1 \mathrm{~m}$ and a vertical root mean square error (RMSE) of $7 \mathrm{~m}$ with a maximum permitted error of $15 \mathrm{~m}$ (Garbrecht and Starks, 1995). While all other non-public data sources were obtained in a 4-year time period at the Deep Loess Station watershed site, the public data for the USGS quad sheet Mineola (7.5 min. quadrangle, 1:24,000 scale) were gathered earlier: the 30-m DEM is from 1970, and the 10-ft contours were mapped in 1952 from aerial photos taken in 1952, field checked in 1956, and published in 1956. The USGS provided this information in $7.5 \mathrm{~min}$. quadrangles through their publicly accessible data server (U.S. Geological Survey, 2002). This is very important since the experimental watersheds were established on loess hillslopes that are classified as highly erodible land with deep gullies; therefore, a change in elevation with time has to be considered as an inherent data uncertainty.

\section{MethodS \\ Data Preprocessing}

The available topographic data sets were originally stored as line (contours only) and point measurements (all other data sets). The 30-m raster DEM was simply converted to a $10-\mathrm{m}$ DEM (Arc command RESAMPLE), while all other data sets were converted to a $10-\mathrm{m}$ raster through an interpolation procedure specifically designed for terrain applications (Arc command TOPOGRID) in the Geographical Information System (GIS) ArcInfo 8 (Environmental Systems Research Institute, Inc., Redlands, Cal.). The TOPOGRID interpolation approach takes advantage of the different types of input data commonly available and the known characteristics of elevation surfaces. TOPOGRID uses a discretized thin plate spline technique (Wahba, 1990) that allows the DEM to follow abrupt changes in terrain, such as streams and ridges. The effects of several non-terrain-motivated interpolation methods on the results of a topographic analysis are described in Desmet (1997).

In contrast to the topographic data of the photogrammetric surveys that were obtained from images taken in less than a second, the DGPS measurements of this watershed required two days. The accuracy of the DGPS signal (1 reading per second) depends therefore on the fixed settings of the receivers (continuous readings with similar settings) but even more on variables such as availability of the satellite and differential correction signals. The number of satellites in view varied over time from 4 to 10 during the 2-day 
measurement period (fig. 3). Besides the spatial variation of readings with a certain number of satellites in view, the distribution of satellites in the sky plays an important role in the overall accuracy of the readings. The dilution of precision (DOP) statistic allows one to estimate the degradation of accuracy of a GPS reading due to the geometry of the satellites. The horizontal DOP (HDOP) by definition is a measure of how the positions of the satellites used to generate the $x$ and $y$ solutions affect the accuracy of the horizontal $(x-y)$ position. Particularly when the northeastern part of the watershed in this study was measured, higher HDOP values, indicating less certainty in the horizontal position solution for a GPS reading, were observed. This higher HDOP coincided with a lower number of available satellites (fig. 3).

Yao and Clark (2000b) indicated that the appropriate statistic to use when considering elevation accuracy is geometric dilution of precision (GDOP), the measure of uncertainty in a GPS position solution in its horizontal (HDOP), vertical (VDOP), and time (TDOP) component. They found a large increase in elevation error when GDOP exceeded 5. Most of the data collected in this study were obtained under good conditions; however, GDOP for the RTK GPS was greater than 5 approximately $10 \%$ of the time.

Of major importance in the accuracy of the RTK GPS data is the type of position solution obtained at each measurement point. To obtain 2 to $6 \mathrm{~cm}$ elevation accuracy, a "fixed" solution is required. If only a "float" solution is obtained, then accuracies will be an order of magnitude poorer (van Diggelen, 1997). In the RTK GPS survey of this watershed, a "float" solution was obtained at approximately $12 \%$ of the positions.

The less accurate a DGPS unit is, the more these accuracy effects influence the quality of the data gathered. Therefore, all gathered points outside the margins of the maximum and minimum elevation of the watershed in the topographic map were dismissed (never more than $0.1 \%$ of all points). The points that passed this test were used to create the $10-\mathrm{m}$ raster DEMs by interpolation. Figure 4 demonstrates the effect of interpolation on two data sets, shown as contour lines in the original and interpolated versions. The surface approximated from the DEM appears much smoother than the original surface, which was forced to include each collected elevation point. The difference between original and interpolated data was less for the higher accuracy RTK GPS data than for the less accurate Ag-DGPS data (fig. 4). For evaluation of the effect of different raster sizes on topographic parameters, refer to Renschler et al. (2001).

\section{Spatial Data Analysis}

The accuracy of the elevation data as well as their derivatives such as slope, upslope drainage area, channel network, and watershed boundary were evaluated by comparing them with the field survey of these features with the Ag-DGPS (V) described earlier. Besides visual comparisons, three quantifying tests were performed to compare each of the alternatives with the most accurate data obtained by the survey-grade RTK GPS measurements.

The topographic parameters elevation, upslope drainage area, and slope in flow direction were investigated. The commonly available TOpographic PArameteriZation (TOPAZ) software (Garbrecht and Martz, 1997) was used for deriving these parameters as well as the watershed boundary delineation and flowpaths draining into channels. Jones
(1998) compared different algorithms used to derive slope gradients from DEMs for their particular precision and accuracy.

\section{Comparison of Selected Checkpoints}

From the 68 checkpoints distributed as a more or less regular lattice over the watershed area, 33 checkpoints were within the common area of all watershed areas delineated by the seven data sets. For these 33 points, averages and standard deviations (SD) of the 10-m DEM data were determined. To compare an alternative data set with the most accurate data set, the coefficient of determination $\left(\mathrm{r}^{2}\right)$, root mean square error (RMSE), and model efficiency (ME) were used as accuracy measures.

The RMSE by definition is given by:

$$
\mathrm{RMSE}=\sqrt{\frac{\sum_{i=1}^{n}\left(P_{i}-O_{i}\right)^{2}}{n}}
$$

where

$$
\begin{aligned}
n= & \text { number of observations } \\
P= & \text { "representative" or predicted model value for a value } \\
& \text { at a certain point } i \text { (e.g., elevation from less accurate } \\
& \text { equipment) } \\
O= & \text { "true" or observed value at the same point } i \text { (e.g., } \\
& \text { elevation from more accurate survey-grade RTK } \\
& \text { GPS). }
\end{aligned}
$$

The ME method (Nash and Sutcliffe, 1970) is usually used to gauge the performance of a series of model results in comparison to observed values:

$$
\mathrm{ME}=1-\frac{\sum_{i=1}^{n}\left(P_{i}-O_{i}\right)^{2}}{\sum_{i=1}^{n}\left(O_{i}-\bar{O}\right)^{2}}
$$

where

$$
\begin{aligned}
& n=\text { number of observations } \\
& P=\text { "representative" or predicted model value for a value } \\
& \quad \text { at a certain point } i \text { (e.g., elevation) } \\
& O=\text { "true" or observed value } \\
& \bar{O}=\text { mean of all observed values. } \\
& \text { ME can range from }-\infty \text { to } 1, \text { and the closer the value is to }
\end{aligned}
$$
1 , the better the model representation. Negative ME values indicate that the fit is poor and unacceptable.

\section{Comparison of Single Pixels}

In addition to checkpoints at selected locations, a pixel-to-pixel comparison between the 10-m raster data layers was calculated and mapped as a continuous layer. This allowed identifying the variation of accuracy within the common watershed areas of an alternative in comparison to the best data available. The absolute error (AE) is the difference between the "true" or observed value $O$ and the "representative" or predicted model value $P$ for a value (e.g., elevation) at a certain pixel. This test was chosen to show the relative accuracy of all other data sets to the two most accurate data sets (RTK GPS and alternative A TIN), which were expected to have the least AE due to their vertical accuracy (see table 1). 

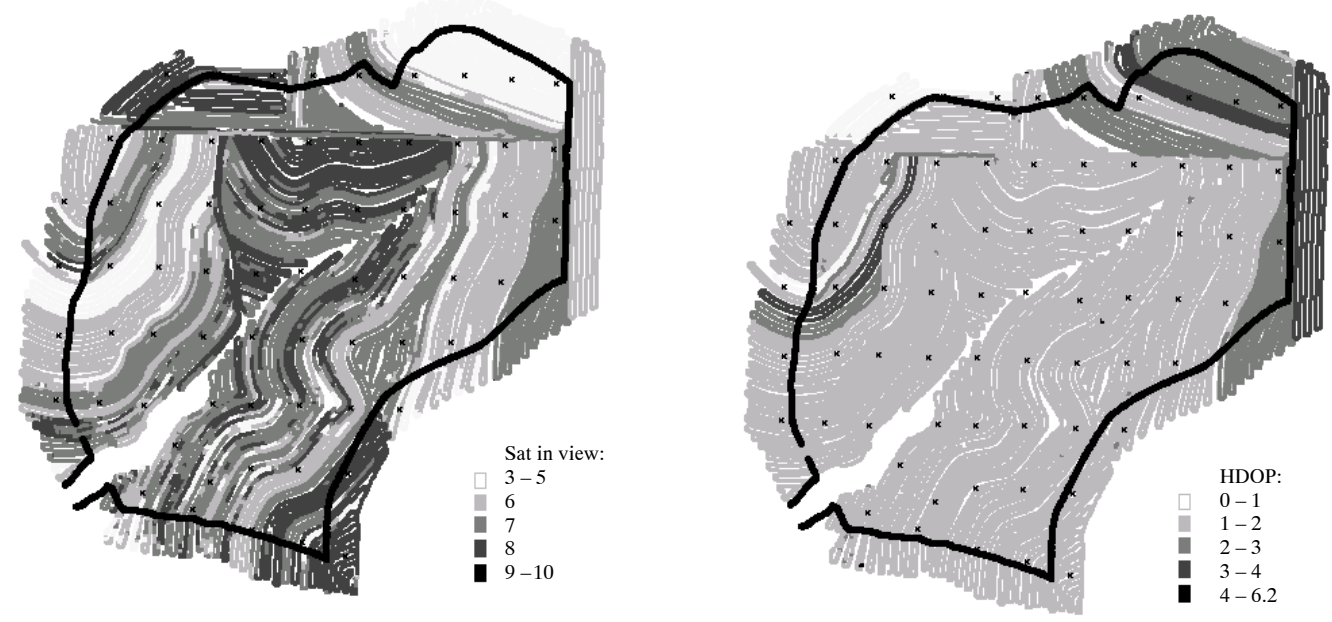

Figure 3. Observed satellites in view (left image) and horizontal dilution of precision (HDOP, right image) at time of measurement for the most accurate data set (RTK GPS).

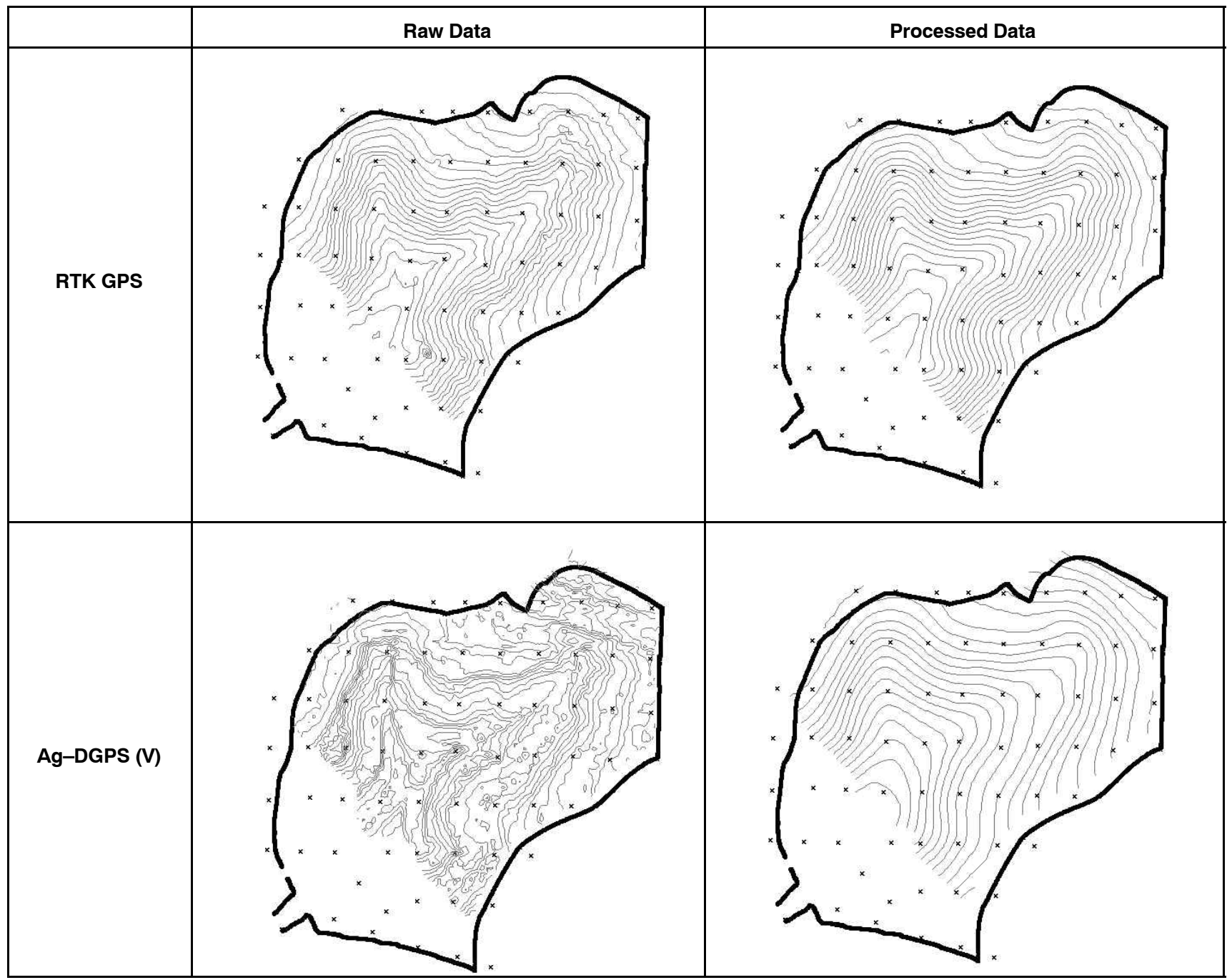

Figure 4. Contour lines from raw data points and derived from a 10-m DEM for the most accurate data set (RTK GPS) and alternative A (Ag-DGPS (V)). 


\section{Comparison of a Pixel Neighborhood}

In contrast to the one-dimensional approach of comparing a series of checkpoints and the two-dimensional approach of a pixel-to-pixel comparison, a new filter was developed to evaluate the spatially distributed RMSE and ME for the central pixel within an $n \times m$ pixel rectangular area. The root mean square error filter value (RMSEFV) is derived as:

$$
\operatorname{RMSEFV}_{x, y}=\sqrt{\frac{\sum_{i=1}^{n} \sum_{j=1}^{m}\left(P_{i j}-O_{i j}\right)^{2}}{n^{*} m}}
$$

where

$x$ and $y=$ coordinates of the central pixel of an $(n \times m)$-sized filter

$n \quad=$ number of pixels in the $x$-direction

$m \quad=$ number of pixels in the $y$-direction

$P \quad=$ "representative" or predicted model value (e.g., elevation) at location $i$ in the $x$-direction and at location $j$ in the $y$-direction within the $(n \times m)$-sized filter

$O=\quad=$ "true" or observed value at location $i$ in the $x$-direction and at location $j$ in the $y$-direction within the $(n \times m)$-sized filter.

The filter to derive the model efficiency filter value (MEFV) can be described mathematically as:

$$
\operatorname{MEFV}_{x, y}=1-\frac{\sum_{i=1}^{n} \sum_{j=1}^{m}\left(P_{i j}-O_{i j}\right)^{2}}{\sum_{i=1}^{n} \sum_{j=1}^{m}\left(O_{i j}-\bar{O}_{n m}\right)^{2}}
$$

where parameters $x, y, n, m, P, i$, and $O$ are defined as in the RMSEFV, and $\bar{O}$ is the mean of all observed values of the $(n \times m)$-sized filter.

RMSEFV and MEFV were applied as filters with $n=7$ by $m=7$ pixels to assure a sufficiently high number of samples $(7 \times 7=49$ samples). The practical reason to apply this filter was to analyze the spatial distribution of more and less accurate areas. Analogous to the approach of test limits described for the pixel-to-pixel comparison, the filters were applied to compare the different alternatives. Note that alternative $\mathrm{B}$ had an area with missing values for the Ag-DGPS (B), which was thus masked and therefore not included in any spatial analysis of alternative $B$.

\section{Results AND Discussion \\ ELEVATION}

A comparison of elevation values for all three alternative data sets with the most accurate RTK GPS data for the 33 selected checkpoints is shown in table 2 . While averages of the GPS data sets were relatively close to each other, within about a $1.5 \mathrm{~m}$ margin that corresponds to the accuracy levels given by the manufacturers (see table 1), the SD of the elevation data was lower for the three less accurately rated DGPS measurements. The coefficient of determination for relating all alternative data sets to the RTK GPS data was greater than 0.95, except for the beacon-corrected Ag-DGPS data set and the 30-m DEM. The 30-m DEM data also had the highest RMSE and a lower ME. The ME values for the three DGPS data sets were the highest, with values greater than 0.9 (table 2).

The pixel-to-pixel comparison of absolute error (AE) between the data sets is graphically shown with an acceptable margin of $\pm 1 \mathrm{~m}$ (fig. 5). The margin of $\pm 1 \mathrm{~m}$, which is approximately the highest vertical precision of alternative $\mathrm{A}$ specified by its manufacturer, was chosen to show the accuracy of all other alternative data sets relative to the two most accurate data sets (RTK GPS and alternative A TIN) and shows the largest area of acceptable AE. The northwestern corner of the watershed area indicated a better agreement between these two data sources. The other DGPS data sets show an agreement for the mid-slope areas in the watershed, while the DLG shows some areas of acceptable AE. The 30-m DEM indicated almost no areas within the acceptable $\mathrm{AE}$ margin of $\pm 1 \mathrm{~m}$.

The analysis of the spatially distributed accuracy of pixel neighborhoods (MEFV approach) was applied with an RMSE of less than 1 (this is a standard set by USGS in their accuracy assessment) and an ME greater than 0.999 (this is almost a perfect match of $M E=1$ ) (fig. 6). The analysis showed that alternatives A and B had the largest areas of agreement with the RTK GPS data, as indicated by RMSE and ME. The filter approach demonstrated the agreement between the four DGPS data sets and the agreement for the northwestern part of the watershed between the RTK GPS and TIN data sets. The data sets for alternative $\mathrm{C}$ showed the least agreement with the RTK GPS data.

Regarding the accuracy of absolute elevation measures, in analyzing topography it really does not matter if the lowest point in the watershed, for instance, has a reference elevation of $100 \mathrm{~m}$ or $1000 \mathrm{~m}$, as long as the elevation of the other points is consistent in relation to that point. The reference elevation differences between the different alternatives bias

\begin{tabular}{|c|c|c|c|c|c|c|}
\hline $\begin{array}{l}\text { Method } \\
\text { (applicability) }\end{array}$ & Data Set & $\begin{array}{c}\text { Average } \\
\text { Elevation } \\
(\mathrm{m})\end{array}$ & $\begin{array}{l}\text { Standard } \\
\text { Deviation } \\
(\mathrm{m})\end{array}$ & $\begin{array}{l}\text { Coefficient of } \\
\text { Determination } \\
\left(\mathrm{r}^{2}\right)\end{array}$ & RMSE & ME \\
\hline Most accurate & RTK GPS & 370.29 & 6.08 & n.a. & n.a. & n.a. \\
\hline \multirow{2}{*}{ Alternative A } & TIN & 368.18 & 6.21 & 0.9810 & 0.0062 & 0.8549 \\
\hline & Ag-DGPS (V) & 370.65 & 4.73 & 0.9595 & 0.0047 & 0.9153 \\
\hline \multirow{2}{*}{ Alternative B } & DGPS (B) & 369.15 & 5.16 & 0.9802 & 0.0045 & 0.9221 \\
\hline & Ag-DGPS (B) & 369.61 & 5.49 & 0.9314 & 0.0048 & 0.9136 \\
\hline \multirow{2}{*}{ Alternative C } & 10-ft DLG & 368.41 & 6.68 & 0.9538 & 0.0064 & 0.8426 \\
\hline & 30-m DEM & 365.74 & 6.12 & 0.8629 & 0.0137 & 0.2856 \\
\hline
\end{tabular}

Table 2. Elevation accuracy at 33 selected checkpoints based on different 10-m raster DEM data sets. 


Alternative A Alternative B

Figure 5. Absolute error (AE) of elevation comparing each single 10-m pixel of different data sources with the most accurate data (RTK GPS). Shaded areas indicate an acceptable area of $\mathrm{AE}<1 \mathrm{~m}$; note that the northeast area of the alternative $\mathrm{B}$ analysis was masked due to equipment failure of $\mathrm{Ag}$ DGPS (B).

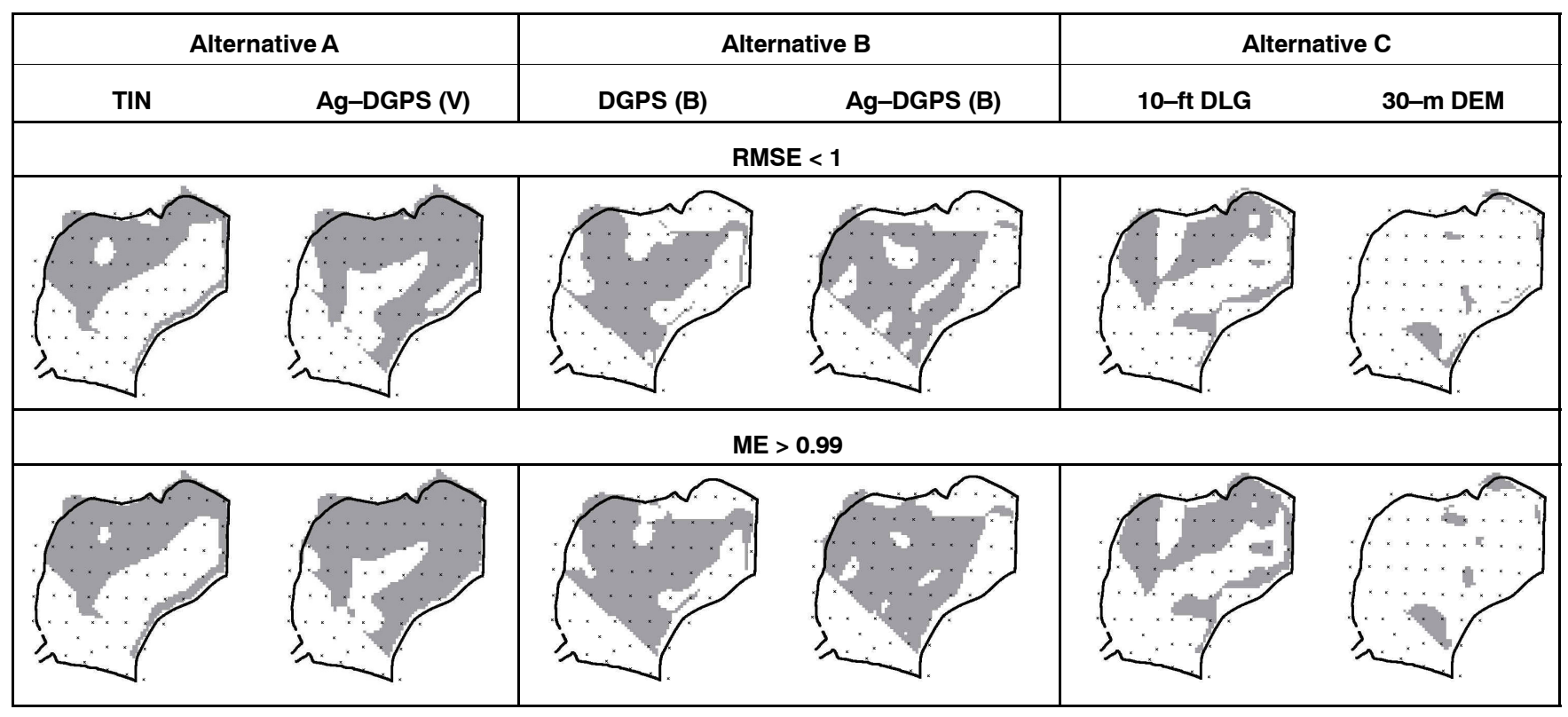

Figure 6. Root mean square error (RMSE) and model efficiency (ME) of elevation comparing a $7 \times 7$-pixel neighborhood of different data sources with the most accurate data (RTK GPS). Shaded areas indicate an acceptable area with a RMSE $<1 \mathrm{~m}$ or ME $>0.99$; note that the northeast area of the alternative B analysis was masked due to equipment failure of Ag-DGPS (B).

the average elevation determined for each of these methods, but since we are investigating topographic derivatives of the different DEMs, this bias is of no importance to further analysis.

\section{Channel and Watershed Delineation}

DEM pixels with a contributing area of 4 ha and larger were marked as potential channel cells for each of the data sources. The dataset-delineated drainage patterns came closest to the field survey mapping of gullies and defined channels when a critical source area (CSA) of 4 ha was chosen for delineating channels in the watershed. The results of the delineation of the drainage pattern as well as the watershed boundaries derived from different data sets are 


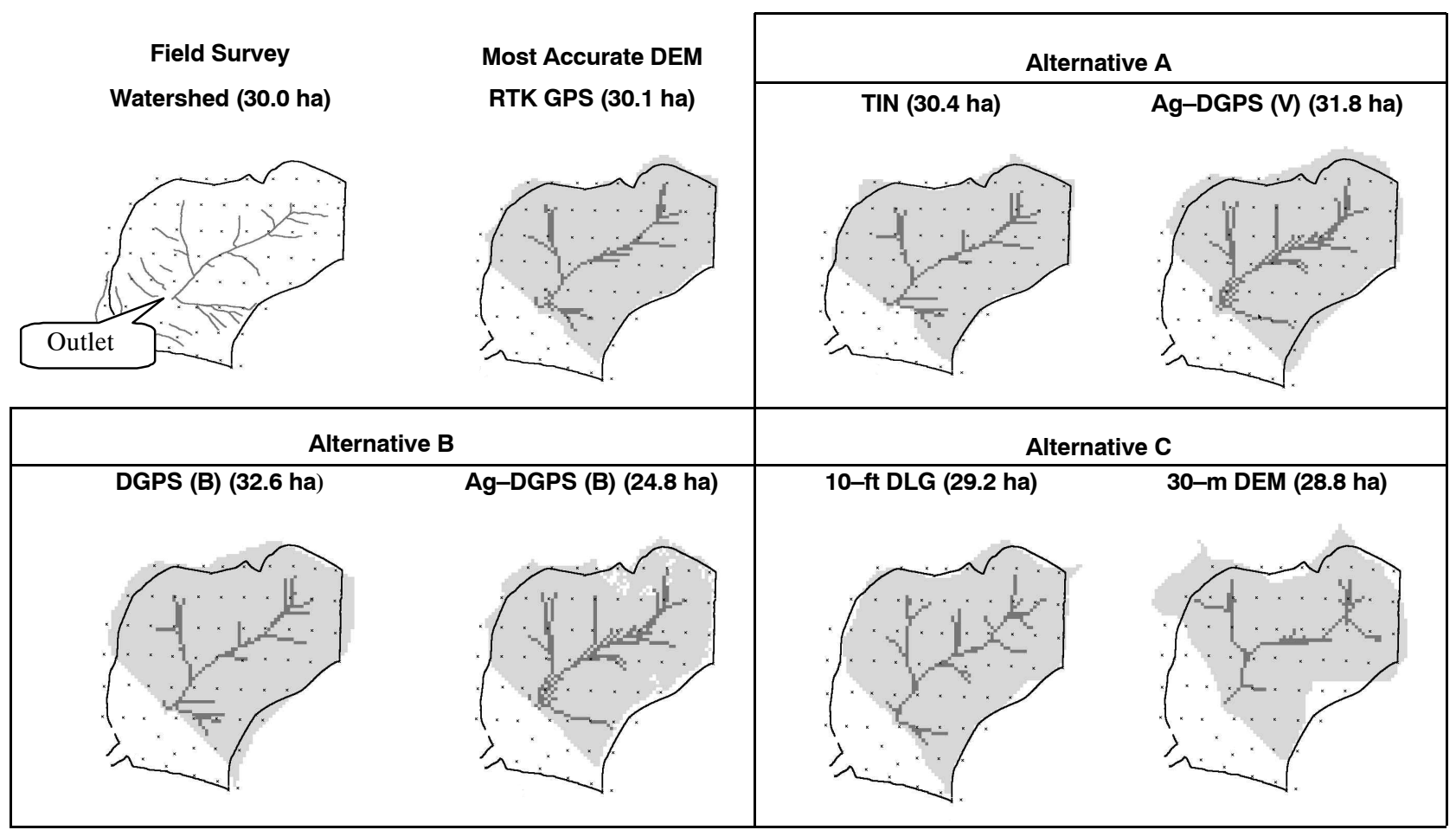

Figure 7. Field survey of ephemeral gullies, delineated watershed boundary, watershed area, and channels. Shaded areas indicate a contributing area $>0.4$ ha.

Table 3. Upslope areas in flow direction at 33 checkpoints based on different data sets.

\begin{tabular}{|c|c|c|c|c|c|c|}
\hline $\begin{array}{l}\text { Method } \\
\text { (applicability) }\end{array}$ & Data Set & $\begin{array}{l}\text { Average } \\
\text { Area } \\
\text { (ha) }\end{array}$ & $\begin{array}{l}\text { Standard } \\
\text { Deviation } \\
\text { (ha) }\end{array}$ & $\begin{array}{c}\text { Coefficient of } \\
\text { Determination } \\
\left(\mathrm{r}^{2}\right)\end{array}$ & RMSE & ME \\
\hline Most accurate & RTK GPS & 0.33 & 1.03 & n.a. & n.a. & n.a. \\
\hline \multirow{2}{*}{ Alternative A } & TIN & 0.11 & 0.15 & 0.0253 & 3.0772 & -0.0221 \\
\hline & Ag-DGPS (V) & 0.69 & 2.82 & 0.0033 & 8.7387 & -7.2429 \\
\hline \multirow{2}{*}{ Alternative B } & DGPS (B) & 0.33 & 0.93 & 0.9584 & 0.6719 & 0.9524 \\
\hline & Ag-DGPS (B) & 0.12 & 0.33 & 0.9229 & 2.2495 & 0.4666 \\
\hline \multirow{2}{*}{ Alternative C } & 10-ft DLG & 0.04 & 0.04 & 0.2393 & 3.1303 & -0.0471 \\
\hline & 30-m DEM & 0.25 & 0.93 & 0.0800 & 3.4976 & -0.3072 \\
\hline
\end{tabular}

shown in figure 7. The drainage patterns of the RTK GPS, the TIN, and the DLG data sets showed the best agreement with the mapped gullies and channels. The two other DGPS data sets have areas with parallel flow rather than a single channel outline. The 30-m DEM drainage pattern differs greatly from the observed pattern. The outline of the watershed boundary (the outlet was set on the outlined channel closest to the existing discharge measurement station; see fig. 7) indicates that all data sets except the 30-m DEM data match the outlined boundary in the field fairly well. A quantitative analysis of the conditions of upslope drainage area (the catchment area for this particular DEM pixel) at the 33 checkpoints is shown in table 3 .

The averages and SD of the upslope drainage areas indicated the fluctuation between conditions determined for a particular location of a point of interest. The coefficient of determination for the upslope areas was the highest for the alternative B data sets, which also have the lowest RMSE and positive ME. Alternative B in this case appeared to be a better choice than the more expensive alternative $A$.

The spatially distributed analysis of the AE in a pixel-topixel comparison of upslope area demonstrated that, with an acceptable margin of an $\mathrm{AE}$ of \pm 0.5 ha (this is equivalent to the $7 \times 7$ pixel filter size of the pixel neighbor comparison below), all data sources were equally good or bad. (Note that one of the GPS systems used for alternative B had an equipment failure, and therefore the northeast area was not taken into account in the analysis.) The unacceptable areas for all data sets were located close to the channel areas (fig. 8).

The analysis when using the filter approach presents a clearer picture (fig. 9). The areas along the main (defined) channels have the highest RMSE. The more sensitive MEFV indicates positive $\mathrm{ME}$ for the upslope areas in an almost random pattern for all data sources, except for the TIN data, which does not have a large coverage area but definitely has the largest accepted areas of all the data sets.

\section{SLOPES IN Flow Direction}

In terms of slopes at the 33 checkpoints, the averages and SDs showed huge differences (table 4). While the most precise measurement techniques produced the best average values in this regard, the alternatives spread around these averages in a wide range, except for the alternative A 


Alternative A Alternative B

Figure 8. Absolute error (AE) of upslope area comparing each single pixel of different data sources with the most accurate data (RTK GPS). Shaded areas indicate an acceptable $\mathrm{AE}<0.5$ ha; note that the northeast area of the alternative $\mathrm{B}$ analysis was masked due to equipment failure of $\mathrm{Ag}-\mathrm{DGPS}$ (B).

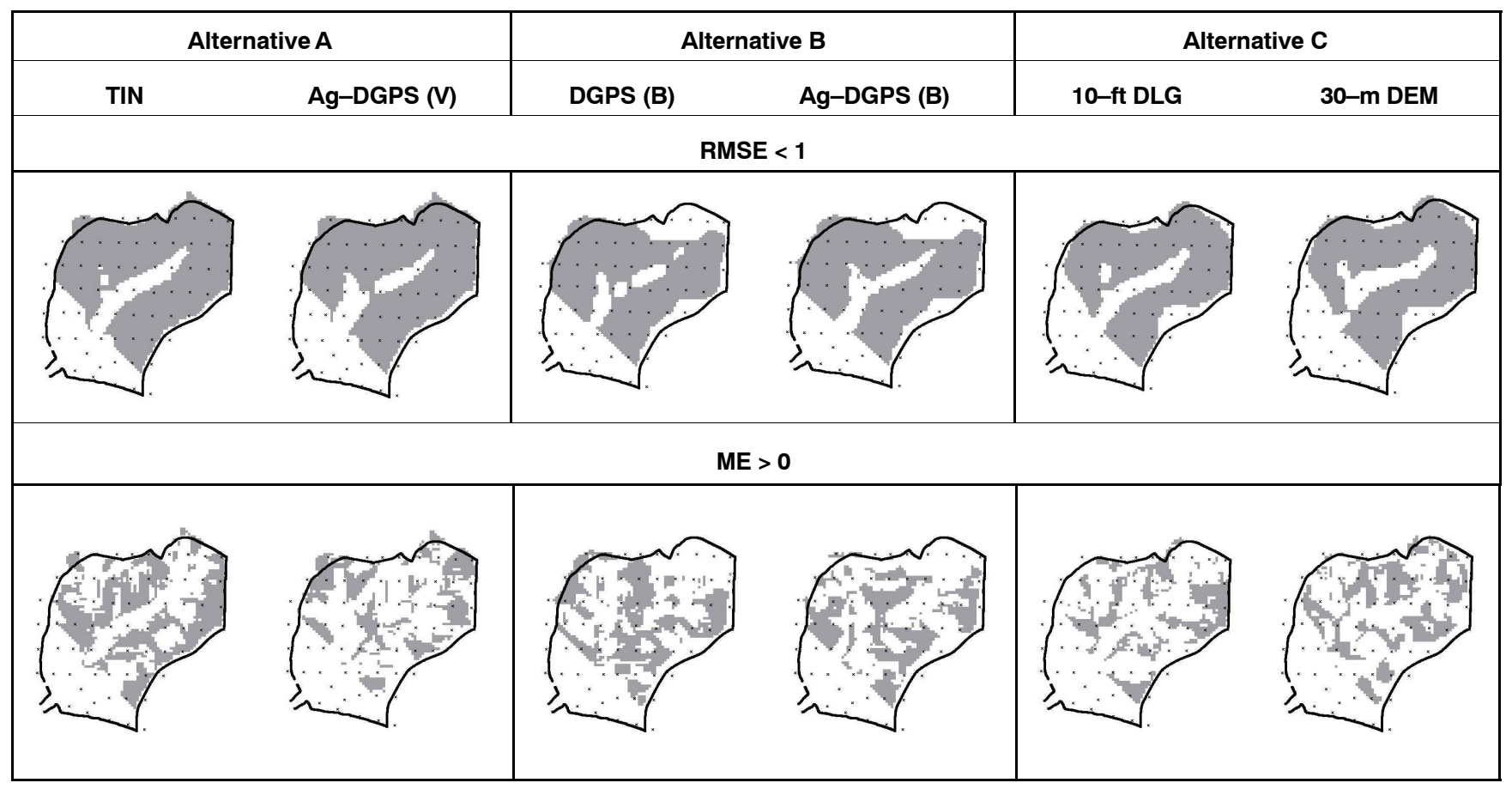

Figure 9. Root mean square error (RMSE) and model efficiency (ME) of upslope areas comparing a $7 \times 7$-pixel neighborhood of different data sources with the most accurate data (RTK GPS). Shaded areas indicate an acceptable RMSE $<1$ and ME $\geq 0 \mathrm{AE}$; note that the northeast area of the alternative $B$ analysis was masked due to equipment failure of Ag-DGPS (B).

photogrammetric survey. For this alternative, the coefficient of determination is also the highest, the RMSE is the lowest, and the ME is the highest. The next best of all the alternatives is the alternative B survey-grade DGPS. All other alternatives perform comparatively poorly for the selected 33 checkpoints.
The spatially distributed analysis of the absolute error (AE) of the slope in the flow direction (fig. 10) presents a better picture. Taking $\pm 2.5 \%$ slope as the acceptance level (that is about the level that one can differentiate in a field survey with simple optical level equipment), the TIN shows the largest acceptance area. Alternative A (Ag-DGPS) and 
Table 4. Slopes in flow direction at 33 checkpoints based on different data sets.

\begin{tabular}{|c|c|c|c|c|c|c|}
\hline $\begin{array}{l}\text { Method } \\
\text { (applicability) }\end{array}$ & Data Set & $\begin{array}{c}\text { Average } \\
\text { Slope } \\
(\%)\end{array}$ & $\begin{array}{c}\text { Standard } \\
\text { Deviation } \\
(\%)\end{array}$ & $\begin{array}{l}\text { Coefficient of } \\
\text { Determination } \\
\left(\mathrm{r}^{2}\right)\end{array}$ & RMSE & $\mathrm{ME}$ \\
\hline Most accurate & RTK GPS & 7.22 & 2.43 & n.a. & n.a. & n.a. \\
\hline \multirow{2}{*}{ Alternative A } & TIN & 7.36 & 2.80 & 0.8560 & 0.1479 & 0.8007 \\
\hline & Ag-DGPS (V) & 5.10 & 1.75 & 0.5101 & 0.3743 & -0.2768 \\
\hline \multirow{2}{*}{ Alternative B } & DGPS (B) & 7.45 & 1.62 & 0.7011 & 0.3081 & 0.1295 \\
\hline & Ag-DGPS (B) & 6.73 & 3.54 & 0.2535 & 0.4321 & -0.7123 \\
\hline \multirow{2}{*}{ Alternative C } & 10-ft DLG & 8.74 & 3.82 & 0.1325 & 0.5522 & -1.6784 \\
\hline & 30-m DEM & 7.82 & 3.27 & 0.1446 & 0.4551 & -0.8188 \\
\hline
\end{tabular}

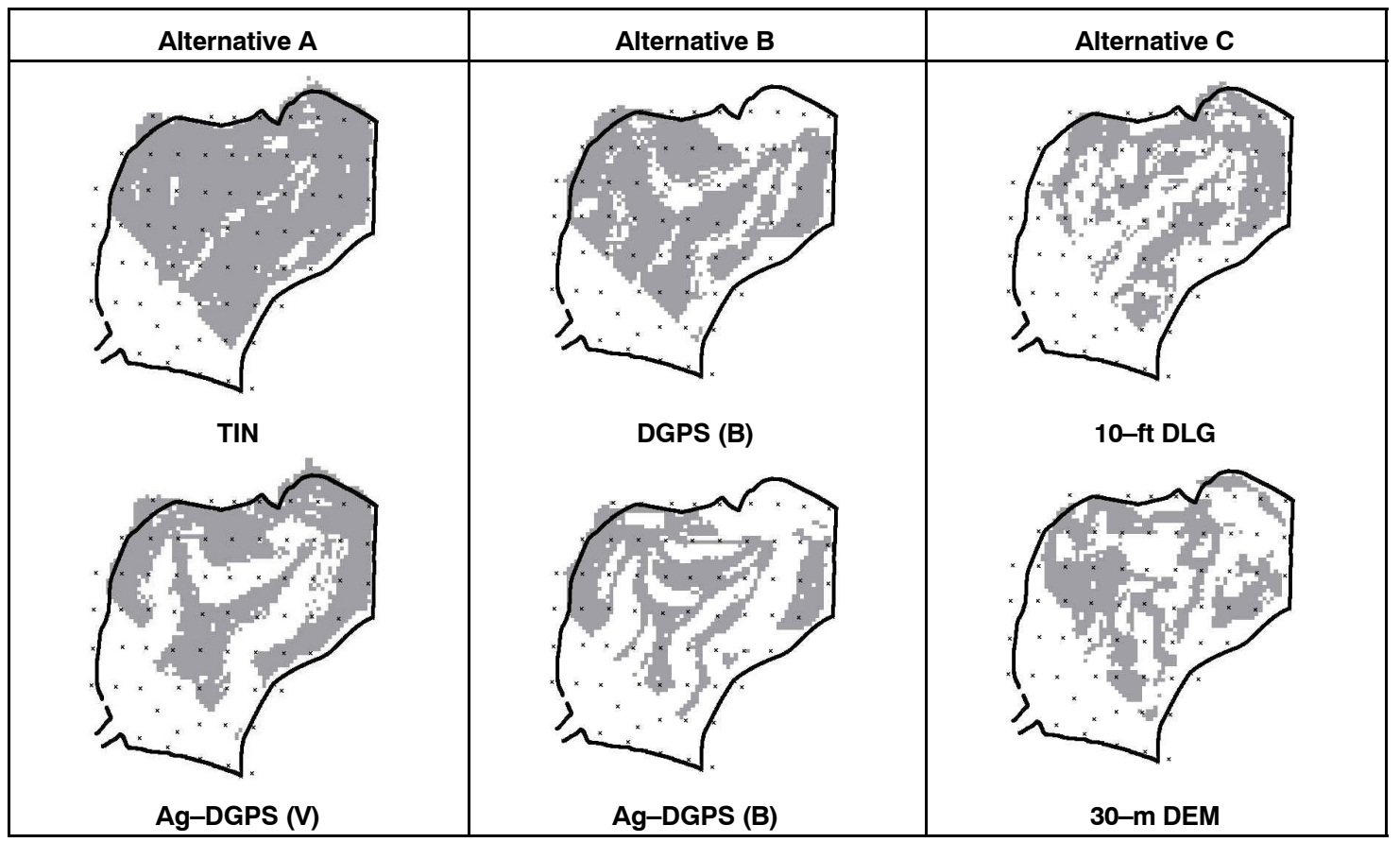

Figure 10. Absolute error (AE) of slope in flow direction comparing each single pixel of different data sources with the most accurate data (RTK GPS). Shaded areas indicate an acceptable $\mathrm{AE} \leq 2.5 \%$; note that the northeast area of the alternative $\mathrm{B}$ analysis was masked due to equipment failure of AgDGPS (B).

alternative B (DGPS) show better acceptance coverage than the other alternatives, but not comparable to the wide acceptance of the TIN.

The more sensitive filter testing approach demonstrated the relative difference of acceptance areas in contrast to the TIN data set (fig. 11). It was clear that alternative A with the TIN and less accurate Ag-DGPS data set produced much better slope estimates than alternatives $\mathrm{B}$ or $\mathrm{C}$.

\section{Conclusions}

The use of digital topographic data sources for analyzing accurate topographic representations in raw elevation data, the determination of topographic parameters, and channel and watershed delineation for decision making purposes all have to be analyzed very carefully because they are all critical to a topographic analysis of the flowpaths and contributing areas in a watershed. The variability of topographic and watershed parameters analyzed within a GIS environment impact the usefulness of the final topographic results for particular locations within the watershed. The three accuracy analysis methods presented here were based on selected checkpoints, absolute error pixel-to-pixel comparisons, and a newly developed filter method for RMSE and model efficiency, and they showed quite different results. The application of only a single evaluation method would not be sufficient to draw the following conclusions:

- The comparison of the accuracy and cost-efficiency of six alternative data sources revealed that if the main purpose of data collection is absolute elevation, then the use of the no-cost options of alternative $\mathrm{C}$ (nationwide readily available data at no cost) was the least accurate.

- The more accurate data sets based on alternatives A (nationwide applicable method with additional costs involved) and B (local/regional dependent method with additional costs involved) provided elevation data at a more or less comparable accuracy level. Therefore, an investment in better GPS equipment might be worthwhile 


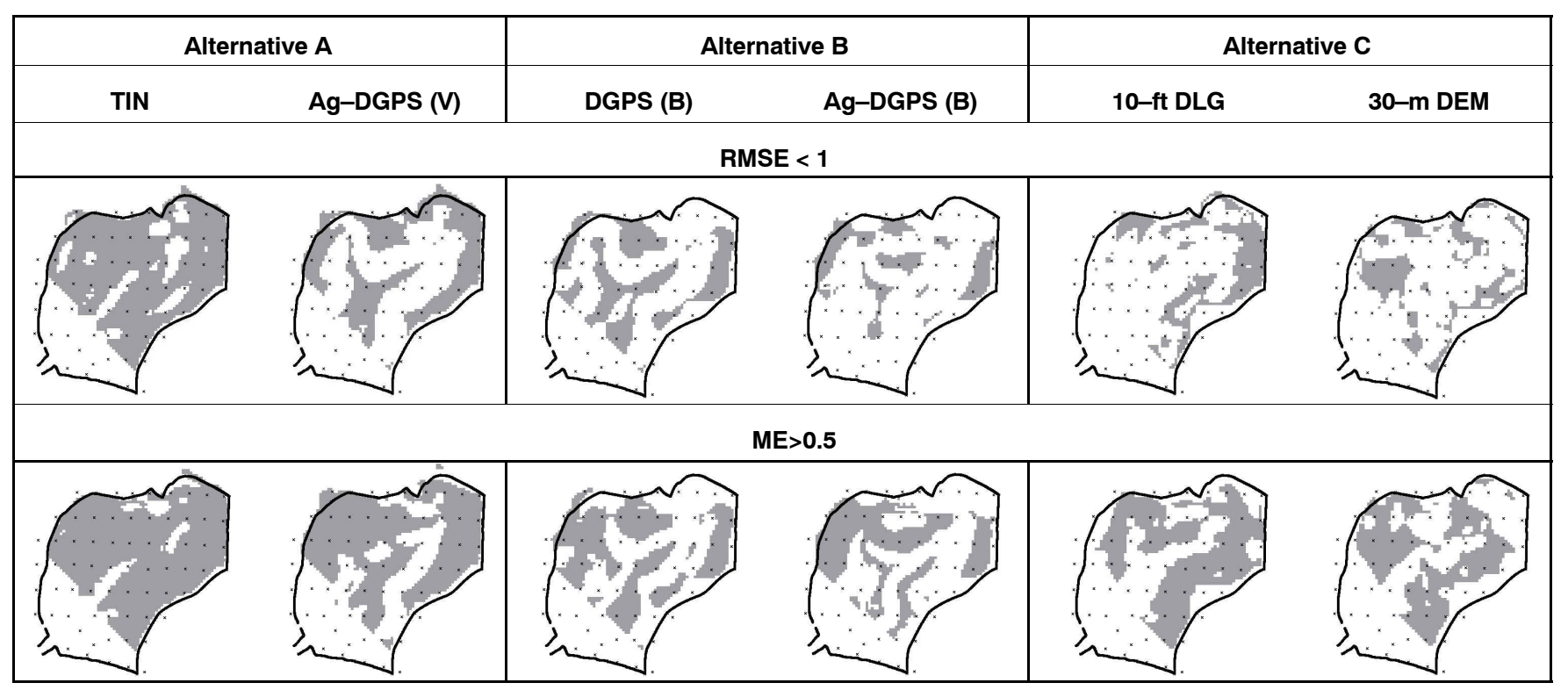

Figure 11. Root mean square error (RMSE) and model efficiency (ME) of slope in flow direction comparing a $7 \times 7$-pixel neighborhood of different data sources with the most accurate data (RTK GPS). Shaded areas indicate an acceptable RMSE $<1$ and ME $\geq 0.5$; note that the northeast area of the alternative B analysis was masked due to equipment failure of Ag-DGPS (B).

in contrast to a contracted photogrammetric survey (alternative A TIN) if one also wants to collect elevation data for other sites or make other uses of GPS-derived information.

- Considering that slope determination for raster (or points) with $10-\mathrm{m}$ spacing would be very labor intensive in a field survey with standard leveling equipment, a decision-maker might rely instead on an approximation based on a TIN, various GPS data sources, or even commonly available data sources by considering the effect of accuracy levels of the different measurement techniques.

- The delineation of the 30 ha-watershed testing site based on TIN and no-cost digital line graphs (DLG) was better than any of the alternative Differential Global Positioning System (DGPS) methods.

- There was no major difference among the alternatives in determining the contributing area of a point in the watershed. However, since GPS data may be gathered continuously while managing fields, using multiple passes and averaging GPS point locations over several seasons would increase the accuracy of elevation data and any derived parameters. For example, Yao and Clark (2000a, 2000b) found that it was possible to develop a decimeter-level-accuracy DEM by averaging at least ten passes of data collected with a sub-meter horizontal accuracy GPS receiver.

\section{ACKNOWLEDGEMENTS}

We gratefully acknowledge the USDA-ARS National Soil Erosion Research Laboratory (NSERL) and the Department of Agricultural and Biological Engineering at Purdue University, West Lafayette, Indiana, for their support of this research. We especially want to thank Robert L. Mahurin and Michael J. Krumpelman from the ARS Cropping Systems and Water Quality Research Unit, Columbia, Missouri, for their efforts in gathering the RTK GPS data. We also acknowledge the advice given by Rex L. Clark of the
University of Georgia in discussing the RTK GPS data gathering in its planning stage.

\section{REFERENCES}

Ackermann, F. 1999. Airborne laser scanning — Present status and future expectations. ISPRS J. Photogram. and Remote Sensing 54: 64-67.

Borgelt, S. C., J. D. Harrison, K. A. Sudduth, and S. J. Birrell. 1996. Evaluation of GPS for applications in precision agriculture. Appl. Eng. in Agric. 12(6): 633-638.

Clark, R. L., and R. Lee. 1998. Development of topographical maps for precision farming with kinematic GPS. Trans. ASAE 41(4): 909-916.

Desmet, P. J. J. 1997. Effects of interpolation errors on the analysis of DEMs. Earth Surf. Processes Landf. 22: 563-580.

Garbrecht, J., and L. W. Martz. 1997. TOPAZ: An automated digital landscape analysis tool for topographic evaluation, drainage identification, watershed segmentation, and subcatchment parameterization: Overview. ARS-NAWQL 95-1. Durant, Okla.: USDA-ARS.

Garbrecht, J., and P. Starks. 1995. Note on the use of USGS Level 1 7.5-minute DEM coverages for landscape drainage analysis. Photogram. Eng. and Remote Sensing 61(5): 519-522.

Jones, K. H. 1998. A comparison of algorithms used to compute hill slope as a property of the DEM. Computers and Geosciences 24(4): 315-323.

Kramer, L. A., M. R. Burkart, D. W. Meek, R. J. Jaquis, and D. E. James. 1999. Field-scale watershed evaluations on deep-loess soils: II. Hydrologic responses to different agricultural land management systems. J. Soil Water Conserv. 54(4): 705-710.

Nash, J. E., and J. V. Sutcliffe. 1970. River flow forecasting through conceptual models: Part I. A discussion of principles. $J$. Hydrology 10(3): 282-290.

Renschler, C. S., T. Cochrane, J. Harbor, and B. Diekkrüger. 2001. Regionalization methods for watershed management Hydrology and soil erosion from point to regional scales. In Sustaining the Global Farm, 1062-1067. D. E. Stott, R. H. Mohtar, and G. C. Steinhardt, eds. West Lafayette, Ind.: International Soil Conservation Organization. 
Shannon, K., C. Ellis, and G. Hoette. 2002. Performance of "low-cost" GPS receivers for yield mapping. ASAE Paper No. 021151. St. Joseph, Mich. ASAE.

Tyler, D. A., D. W. Roberts, and G. A. Nielsen. 1997. Location and guidance for site-specific management. In The State of Site-Specific Management for Agriculture, 161-182. F. J. Pierce and E. J Sadler, eds. Madison, Wisc.: ASA, CSSA, SSSA.

U.S. Bureau of the Budget. 1947. United States National Map Accuracy Standards. Revised 17 June 1947.

U.S. Geological Survey. 2002. USGS Geographic Data Download. Available at: http://edc.usgs.gov/geodata/. Accessed on 16 August 2002.

van Diggelen, F. 1997. GPS and GPS+GLONASS RTK. In Proc. ION-GPS 97, 139-144. Alexandria, Va.: The Institute of Navigation.

Wahba, G. 1990. Spline Models for Observational Data. Vol. 59 in CBMS-NSF Regional Conference Series in Applied Mathematics. Philadelphia, Pa.: Society for Industrial and Applied Mathematics.
Wang, Y., B. Mercer, V. C. Tao, J. Sharma, and S. Crawford. 2001. Automatic generation of bald earth digital elevation models from digital surface models created using airborne IFSAR. Paper presented at ASPRS Annual Meeting 2001. Bethesda, Md.: American Society for Photogrammetry and Remote Sensing. Available at: www.intermaptechnologies.com/PDF file/ asprs2001_Intermap_E.pdf. Accessed on: 16 Dec 2002.

Wilson, J. P., D. J. Spangrud, G. A. Nielsen, J. S. Jacobsen, and D. A. Tyler. 1998. Global positioning system sampling intensity and pattern effects on computing topographic attributes. Soil Sci. Soc. Amer. J. 62: 1410-1417.

Yao, H., and R. L. Clark. 2000a. Development of topographic maps for precision farming with medium accuracy GPS receivers. Appl. Eng. in Agric. 16(6): 629-636.

2000b. Evaluation of sub-meter and 2 to 5 meter accuracy GPS receivers to develop digital elevation models. Precision Agriculture 2(2): 189-200. 
